\title{
Rapid Detection of H. Pylori in Antral Biopsy Specimens by Amplification of a Conserved Sequence in the Dupa Gene
}

\author{
Ghazaleh Sadeghi ${ }^{1}$, Shahin Najar Pirayeh ${ }^{1}$, Mojgan Forutan ${ }^{2}$ and Amin Talebi Bezmin Abadi*1 \\ ${ }^{1}$ Department of Bacteriology, Tarbiat Modares University, Iran
}

${ }^{2}$ Department of Shahid Beheshti, University of Medical Sciences, Iran

Received: February 01, 2018; Published: February 15, 2018

*Corresponding author: Amin Talebi Bezmin Abadi, Department of Bacteriology, Faculty of Medical Sciences, Tarbiat Modares University, Tehran, Iran, Tel: 9882884883; Email: Amin.TALEBI@MODARES.AC.IR

\section{Abstract}

Background and aims: Helicobacter pylori (H. pylori) is a colonizer in the gastric mucosa of more than $50 \%$ of the human population. Complications due to this bacterium include chronic gastritis, gastric mucosa-associated lymphoid tissue lymphoma, peptic ulcer and gastric adenocarcinoma. The aim of this study was molecular detection of H. pylori in biopsy samples by amplification of conserved sequences of dupA gene.

Materials and Methods: The in silico study for detection of conserved region in dupA was performed. Seventy-nine biopsy samples were collected and DNA was extracted from them. The polymerase chain reaction (PCR) was performed to amplify dupA conserved region. The glmM gene was also amplified as a standard control alongside the dupA gene.

Results: Results of 79 samples, 31 and 48 were collected from males and female patients, respectively. The age range of patients was 13-85 years; Mean \pm SD (49.68 \pm 18.82 ).The patients' complications included $35.4 \%$ reflux (13.92\% males and $21.52 \%$ females), $32.9 \%$ gastritis ( 7.59 males and $25.31 \%$ females) and $8.9 \%$ peptic ulcer (2.58 males and $6.32 \%$ females). The PCR amplification of dupA showed $98 \%$ and $100 \%$ sensitivity and specificity, respectively, whereas results for glmM were $26 \%$ and $100 \%$, respectively.

Conclusion: The findings exhibited that the amplification of dupA conserved region with a high sensitivity and specificity can be considered as a rapid diagnostic method for $\mathrm{H}$. pylroi identification in biopsy specimens.

Keywords: Helicobacter pylori; biopsy samples; Diagnosis; dupA gene; glmM gene

Abbreviations: RUT: Rapid Urease Test; UBT: Urea Breath Test; SAT: Stool Antigen Test

\section{Introduction}

Helicobacter pylori (H. pylori) colonizes half of the human population worldwide and is known as the causative agent of gastric ulcers and adenocarcinoma, chronic gastritis, gastric mucosa-associated lymphoid tissue lymphoma [1]. Diagnosis of $\mathrm{H}$. pylori is performed by several methods each with own advantages, disadvantages and limitations. A classic route to categorize the methods is dependent upon whether or not an endoscopy is essential. Those tests based on biopsy include culture, histological evaluation, PCR and the rapid urease test (RUT), all of which are conducted on tissue obtained during endoscopy. As an alternative way, the urea breath test (UBT), stool antigen test (SAT) and serology can be performed as non-invasive procedures. A second way for classification of these tests is according to if they are used before or after $\mathrm{H}$. pylori eradication treatment [2].

In the histological examination, in which both antrum and corpus biopsies may be required, critical information regarding the mucosa (e.g., presence and severity of inflammation, dysplasia, glandular atrophy, intestinal metaplasia and neoplasia) will be provided [3-6]. The sensitivity and specificity of histology vary from $53 \%$ to $90 \%$, relating to the pathologist's experience and density of $\mathrm{H}$. pylori colonization. Increase in the number of biopsies and application of specific stains can enhance the sensitivity of this examination [7]. Several other Helicobacter species may be also present in gut and misdiagnosed with H. pylori. Fluorescent in situ hybridization (FISH) is a new method for specific characterization of $\mathrm{H}$. pylori features, but this method is laborious, expensive, and not utilized in clinical practice [8-9]. The culture method is ideal when using a recently obtained gastric biopsy specimen because of low number of flora in most of cases, having sensitivity of $90 \%$ and specificity of $100 \%$ if fulfilled under optimal conditions [10].

However, for the delicateness of $\mathrm{H}$. pylori and needing to culture as soon as possible, always it is not true. For this purpose, 
biopsy samples can be taken in a transport medium (e.g., Stuart's medium) for up to $24 \mathrm{~h}$ at $4{ }^{\circ} \mathrm{C}$. Culture of $\mathrm{H}$. pylori is performed on several media such as Skirrow agar, Pylori-agar, Wang media, and others with specific antibiotics to inhibit bacterial body flora, and nonselective media (e.g., blood agar, Columbia blood agar, and others). Culture is the most specific method, but depends on personal experience, specimen quality, and use of transport media [11]. It is in general not considered a routine diagnostic way and is not available in most of medical institutions worldwide. Sometimes the method is conducted when antibiotic susceptibility testing is required [2].

PCR allows researchers to detect the bacterium even in very low numbers, however there the possibility that dead bacterial population be present in the gut mucosa and give positive result in this test. PCR results are faster than many other diagnostic methods for identification of bacterial genotypes and when epidemiological studies are performed [12-14]. Some other diagnostic methods have been applied for $\mathrm{H}$. pylori such as urease breath test and stool antigen tests may also be performed. The aims of this study were detection of $\mathrm{H}$. pylori prevalence and evaluation of it in biopsy samples by amplification of conserved region of dupA gene.

\section{Materials and Methods}

The in silico study , For this purpose, a pilot study was performed until June 2015. Six-hundred and seventy-four various sequences of dupA gene were entered to the Seaview (Version 4.5.4) software and were assessed initially (puzzling). For detection of conserved region in dupA, 100 preferred sequences with more overlapping regions were adopted (Figure 1). The PCR was designed using specific primers for the overlapping region.

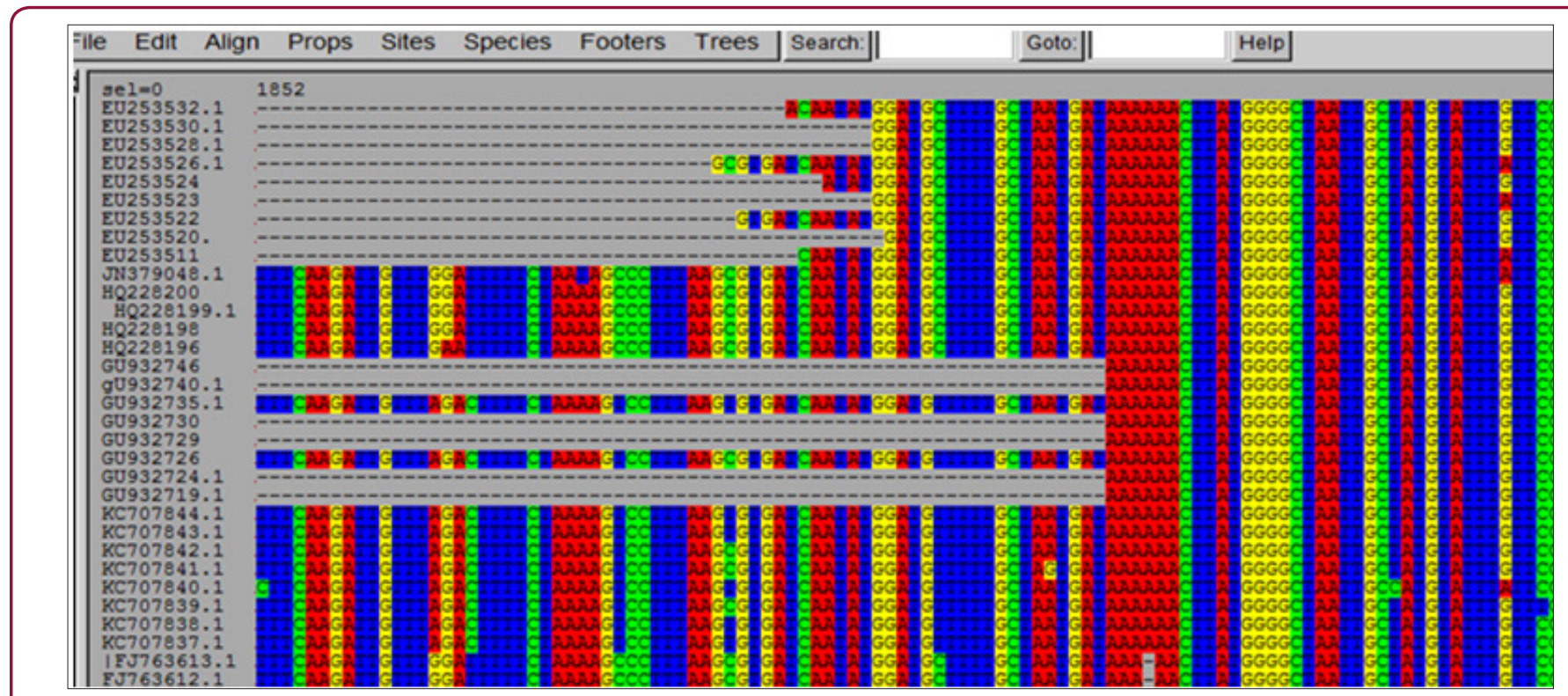

Figure 1: Detection of conserved region in dupA gene.

Biopsy Samples Collection: Seventy-nine biopsy samples were collected from patients with various complications including indigestion, stomach pain, nausea, reflux, inflammatory bowel disease, gastritis, fatty liver disease, duodenal ulcers, gastric ulcers and other symptoms by gastroenterologist physician. The specimens were transported to the laboratory in micro-tubes containing tyoglycolate medium and stored at $-80^{\circ} \mathrm{C}$ until use in the test.

DNA extraction: DNA was extracted from biopsy samples by utilizing YTA Genomic DNA Extraction Mini kit (Cat No: YT9030) according to the manufacturer's instructions. The kit contains TG1 and TG2 buffers, proteinase k, mini-TG column, W1 buffer, collection tube, wash buffer, elution tube and micro pestle (for tissue homogenization).

PCR amplification of dupA and glmM genes: PCR technique was performed to detect dupA conserved region to amplify $110 \mathrm{bp}$ size product. The glmM gene was also amplified as a standard control alongside dupA gene for the amplification of a product with 294bp size. The specific primers included:glmMF: 5'AAGCTTTTAGGGGTGTTAGGGGTTT3',glm MR:'5AAGCTTACTTTCTAACACTAACGC3', dupAF: 5'CATGGCGTTTCAAAAAATATCTCAA3’, and dupAR: 5'TTCATCAGTATCTTTTGTGGGGTA3'. PCR conditions for dupA gene included as following: $93^{\circ} \mathrm{C}$ for $60 \mathrm{~s}, 61^{\circ} \mathrm{C}$ for $60 \mathrm{~s}$, and $72^{\circ} \mathrm{C}$ for $60 \mathrm{~s}$. The thermal profile conditions for glmM were similar to those for dupA gene and both were run for 35 cycles. The strain 26695 was the reference strain used in this assay.

\section{Results}

Thirty-one and 48 patients were males (mean age $=47.70 \pm 1.37$ ) and females (mean age $=17.39 \pm 0.47$ ), respectively. The age range of patients in this study has been demonstrated in (Figure 2). The patients' complications included $35.4 \%$ reflux (13.92\% males and $21.52 \%$ females), $32.9 \%$ gastritis (7.59 males and $25.31 \%$ females) and $8.9 \%$ peptic ulcer ( 2.58 males and $6.32 \%$ females). The ages of 33, 36 and 49 years were predominant age groups. Twentythree patients had a history of gut infection, but 56 were healthy individuals. 


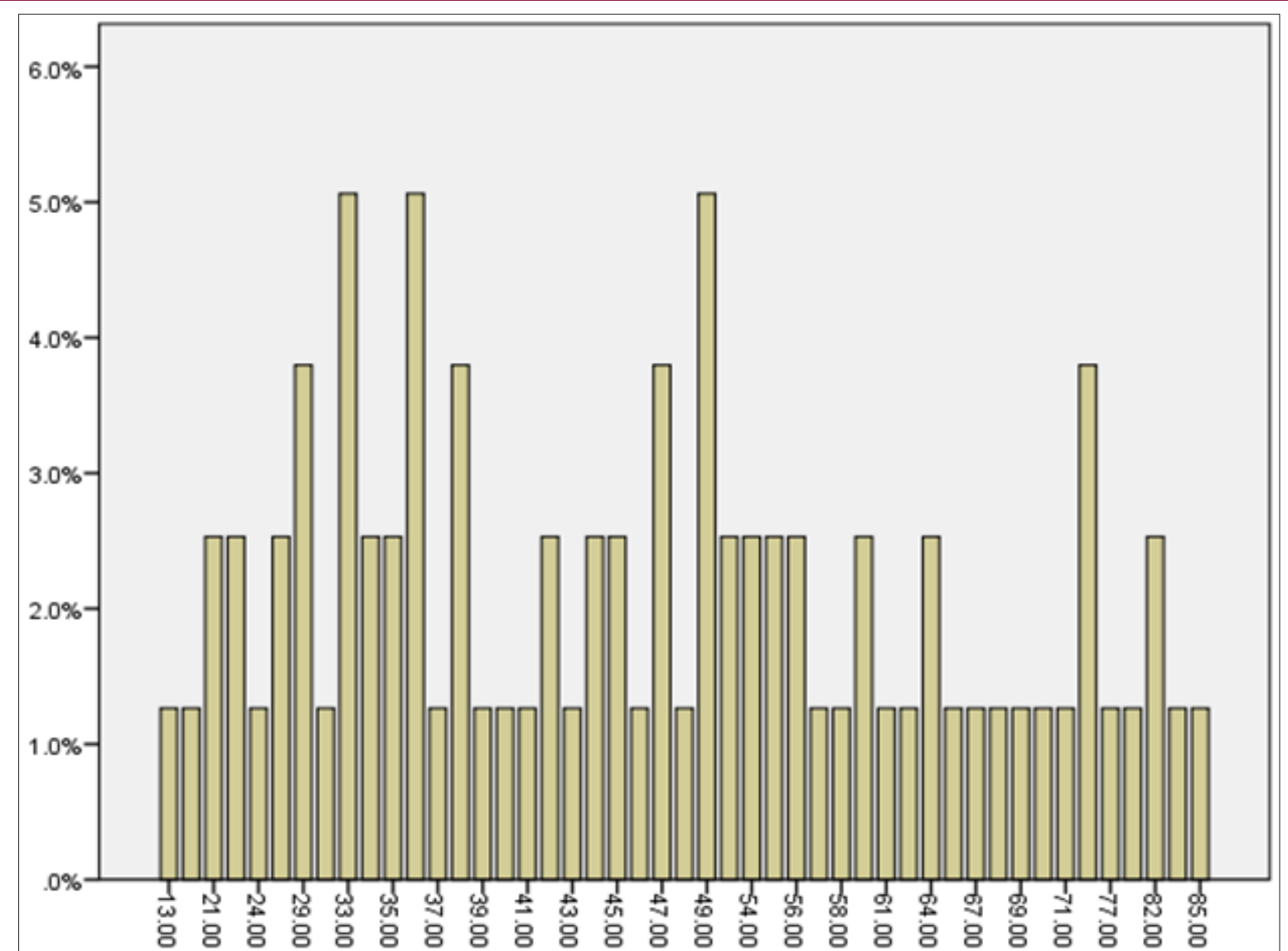

Figure 2: The age distribution of patients in this study.

The PCR amplification of dupA showed 98\% and 100\% sensitivity and specificity, respectively, whereas results for glmM were $26 \%$ and $100 \%$, respectively. The relation between dupA and glmM and gastrointestinal diseases was not significant ( $p$ value $=0.443$ ). Therefore, $\mathrm{H}$. pylori was not considered as the only gastrointestinal disease.

\section{Discussion}

The accurate diagnosis of $\mathrm{H}$. pylori is a critical and effective factor for management of many gastrointestinal diseases. Several invasive and non-invasive methods are available in the H. pylori and each has its advantages and drawbacks. These methods have sensitivity and specificity of approximately 90\%. Choosing each method is according to the availability and patient's conditions. The invasive methods include endoscopy, culture, rapid urease test and some molecular methods. Urea breath test, fecal antigen test and serology are among those non-invasive methods [15]. PCR method has a higher sensitivity and specificity which can cover many other queries such as needing to rapid and non-invasive diagnosis, determination of mutations related to the antibiotic resistance alongside virulence factors encoding genes, and genotyping [1618].

Several genes have been amplified for the diagnosis of $\mathrm{H}$. pylori such as 16srRNA, ureA, glmM, babA2, rpoB, ssA, cagA, hopQ, icd and PPIase [19-20]. The ureC gene also called glmM encodes the phosphor-glucoseamin mutase, is widely used for the $\mathrm{H}$. pylori diagnosis [21]. We determined sensitivity and specificity of $98 \%$ and $100 \%$ for dupA and $26 \%$ and $100 \%$ for glmM genes, respectively among biopsy samples. The glmM low sensitivity makes a drawback in the diagnosis of H. pylori [22]. The dupA gene placed in a plasticity zone of $\mathrm{H}$. pylori genome, have shown to be related to duodenal ulcers [23-25].

Two studies assessing different diagnostic methods in specific settings revealed that histology was the most accurate test: Choi et al. [27] evaluated several methods for H. pylori detection in patients with peptic ulcer which 157 were bleeding and 247 were nonbleeding. The sensitivity and specificity of histology were 92.5 and 96\%, and 85 and $92 \%$ for rapid urease test (RUT), 40 and $100 \%$ for culture, and 97 and 56\% for serology, respectively. The culture and RUT sensitivities were significantly higher in non-bleeding patients compared to bleeding patients. By contrast, histology was valid and accurate regardless of bleeding. Tian's study [27] demonstrated in a meta-analysis evaluating diagnostic methods of $\mathrm{H}$. pylori in patients with partial gastrectomy.

The sensitivity and specificity included 93 and $85 \%$ for histology, 79 and $94 \%$ for RUT and 77 and $89 \%$ for urea breath test (UBT), respectively. Their study concluded that histology method was the most accurate test in this setting. In this study, female patients and age groups of 33, 36 and 49 years were more infected with $\mathrm{H}$. pylori which was somewhat in accordance with Gimire's study in which most of patients infected with H. pylori were in 21- 
40 years old, but their study showed no association with gender (55.8\% male versus $44.2 \%$ female) of patients [28]. Kadhim reported a significant difference between male and female patients infected with H. pylori [29]. In our study, the patients' complications included $35.4 \%$ reflux (13.92\% males and $21.52 \%$ females), $32.9 \%$ gastritis (7.59 males and $25.31 \%$ females) and $8.9 \%$ peptic ulcer (2.58 males and $6.32 \%$ females).

Nordenstdt et al showed that among 491 individuals, 40.7\% had gastritis and $20.5 \%(n=41)$ were H. pylori negative [30]. In a study by Abrams, the incidence of reflux-related cardia cancer showed gradually increased, whereas cardia cancer caused by $\mathrm{H}$. pylori has decreased progressively since the mid-20th century [31]. In a study by Franklin, 44.9\% (35/78) of adolescent patients with H. pylori exhibited chronic gastritis [32]. In this investigation, no significant relation was observed between the presence of dupA and glmM genes and clinical findings including gastritis, peptic ulcer and reflux. This is in agreement with studies from Brazil and South Africa [33,34].

\section{References}

1. Plummer M, Franceschi S, Vignat J, Forman D, de Martel C (2015) Global burden of gastric cancer attributable to Helicobacter pylori. Int J Cancer 136(2): 487-490.

2. Garza-González E, Perez-Perez GI, Maldonado-Garza HJ, Bosques-Padilla FJ (2014) A review of Helicobacter pylori diagnosis, treatment, and methods to detect eradication. World J Gastroenterol 20(6): 1438-1449.

3. Genta RM, Graham DY (1994) Comparison of biopsy sites for the histopathologic diagnosis of Helicobacter pylori: a topographic study of H. pylori density and distribution. Gastrointest Endosc 40(3): 342-345.

4. Satoh K, Kimura K, Taniguchi Y, Kihira K, Takimoto T, et al. (1998) Biopsy sites suitable for the diagnosis of Helicobacter pylori infection and the assessment of the extent of atrophic gastritis. The Am J gastroenterol 93(4): 569-573.

5. Van Ijzendoorn M, Laheij R, De Boer W, Jansen J (2005) The importance of corpus biopsies for the determination of Helicobacter pylori infection. Neth J Med 63(4): 141-145.

6. Lan HC, Chen TS, Li AFY, Chang FY, Lin HC (2012) Additional corpus biopsy enhances the detection of Helicobacter pylori infection in a background of gastritis with atrophy. BMC gastroenterol 12(1): 182.

7. Dursun M, Yilmaz S, Yükselen V, Kilinç N, Canoruç F, et al. (2004) Evaluation of optimal gastric mucosal biopsy site and number for identification of Helicobacter pylori, gastric atrophy and intestinal metaplasia. Hepatogastroenterology 51(60): 1732-1735.

8. Rüssmann H, Kempf VA, Koletzko S, Heesemann J, Autenrieth IB (2001) Comparison of fluorescent in situ hybridization and conventional culturing for detection of Helicobacter pylori in gastric biopsy specimens. J clin microbiol 39(1): 304-308.

9. Camorlinga-Ponce M, Romo C, Gonzalez-Valencia G, Munoz O, Torres J (2004) Topographical localisation of cagA positive and cagA negative Helicobacter pylori strains in the gastric mucosa; an in situ hybridisation study. J clin pathol 57(8): 822-828.

10. Hirschl AM, Makristathis A (2007) Methods to detect Helicobacter pylori: from culture to molecular biology. Helicobacter 12(s2): 6-11.

11. Ndip RN, MacKay WG, Farthing MJ, Weaver LT (2003) Culturing Helicobacter pylori from clinical specimens: review of microbiologic methods. J Pediatr Gastroenterol Nutr 36(5): 616-622.

12. Whitmire JM, Merrell DS (2012) Successful culture techniques for Helicobacter species: verification of Helicobacter identity using $16 \mathrm{~S}$
rRNA gene sequence analysis. Helicobacter Species: Methods Mol Biol 921: 37-40.

13. Rimbara E, Sasatsu M, Graham DY (2013) PCR detection of Helicobacter pylori in clinical samples. Methods Mol Biol 943: 279-287.

14. Duś I, Dobosz T, Manzin A, Loi G, Serra C, et al. (2013) Role of PCR in Helicobacter pylori diagnostics and research--new approaches for study of coccoid and spiral forms of the bacteria. Postepy Hig Med Dosw (Online) 67: 261-268.

15. Wang YK, Kuo FC, Liu CJ, Wu MC, Shih HY, et al. (2015) Diagnosis of Helicobacter pylori infection: Current options and developments. World J Gastroenterol. WJG 21(40): 11221.

16. Calvet X, Ramírez Lázaro MJ, Lehours P, Mégraud F (2013) Diagnosis and epidemiology of Helicobacter pylori infection. Helicobacter 18(s1): 5-11.

17. Lehours P, Mégraud F (2011) Helicobacter pylori molecular diagnosis. Expert review of molecular diagnostics 11(4): 351-355.

18. Almeida N, Donato MM, Romãozinho JM, Luxo C, Cardoso O, et al. (2015) Correlation of helicobacter pylori genotypes with gastric histopathology in the central region of a south-European Country. Dig Dis Sci 60(1): 7485.

19. Russo F, Notarnicola M, Di Matteo G, Leoci C, Caruso ML, et al. (1999) Detection of Helicobacter pylori cagA gene by polymerase chain reaction in faecal samples. Eur J Gastroenterol Hepatol 11(3): 251-256.

20. Ho GY, Windsor HM (2000) Accurate diagnosis of Helicobacter pylori: polymerase chain reaction tests. Gastroenterol Clin North Am 29(4): 903-915.

21. De Reuse H, Labigne A, Mengin-Lecreulx D (1997) The Helicobacter pylori ureC gene codes for a phosphoglucosamine mutase. J bacteriol 179(11): 3488-3493.

22. Germani Y, Dauga C, Duval P, Huerre M, Levy M, et al. (1997) Strategy for the detection of Helicobacter species by amplification of 16S rRNA genes and identification of $\mathrm{H}$. felis in a human gastric biopsy. Res microbiol 148(4): 315-326.

23. Wang My, Chen C, Shao C, Wang Sb, Wang Ac, et al. (2015) Intact longtype DupA protein in Helicobacter pylori is an ATPase involved in multifunctional biological activities. Microb pathog 81: 53-59.

24. Hussein NR, Mohammadi M, Talebkhan Y, Doraghi M, Letley DP, et al. (2008) Differences in virulence markers between Helicobacter pylori strains from Iraq and those from Iran: potential importance of regional differences in H. pylori-associated disease. J Clin Microbiol 46(5): 17741749.

25. Zhang Z, Zheng Q, Chen X, Xiao S, Liu W, et al. (2008) The Helicobacter pylori duodenal ulcer promoting gene, dupA in China. BMC Gastroenterol $8: 49$.

26. Choi YJ, Kim N, Lim J, Jo SY, Shin CM, et al. (2012) Accuracy of diagnostic tests for Helicobacter pylori in patients with peptic ulcer bleeding. Helicobacter 17(2): 77-85.

27. Tian XY, Zhu H, Zhao J, She Q Zhang GX (2012) Diagnostic performance of urea breath test, rapid urea test, and histology for Helicobacter pylori infection in patients with partial gastrectomy: a meta-analysis. J Clin Gastroenterol. 46(4): 285-292.

28. Ghimire P, Ghimire P, Goel R, Bahl D (2015) Spectrum of Changes in Gastric Mucosa with Helicobacter Pylori Infection. Journal of Nepalgunj Medical College 12(1): 29-31.

29. Kadhim G, Maidin M, Omar H, Ismail A (2015) Identification of Vitamin B12 Deficiency in Helicobacter pylori Infected Patients. Journal of Bioengineering \& Biomedical Sciences 5(3): 1.

30. Nordenstedt H, Graham DY, Kramer JR, Rugge M, Verstovsek G, et al. (2013) Helicobacter pylori-negative gastritis: prevalence and risk factors. The American journal of gastroenterology 108(1): 65-71. 
31. Abrams JA, Gonsalves L, Neugut AI (2013) Diverging trends in the incidence of reflux-related and Helicobacter pylori-related gastric cardia cancer. J Clin Gastroenterol 47(4): 322-327.

32. Franklin AL, Koeck ES, Hamrick MC, Qureshi FG, Nadler EP (2015) Prevalence of Chronic Gastritis or Helicobacter pylori Infection in Adolescent Sleeve Gastrectomy Patients Does Not Correlate with Symptoms or Surgical Outcomes. Surg infect 16(4): 401-404.

33. Gomes LI, Rocha GA, Rocha AM, Soares TF, Oliveira CA, Bittencourt PF, et al. (2008) Lack of association between Helicobacter pylori infection with
dupA-positive strains and gastroduodenal diseases in Brazilian patients. Int J Med Microbiol 298(3): 223-230.

34. Pacheco AR, Proença-Módena JL, Sales AI, Fukuhara Y, Da Silveira WD, et al. (2008) Involvement of the Helicobacter pylori plasticity region and cag pathogenicity island genes in the development of gastroduodenal diseases. European journal of clinical microbiology \& infectious diseases 27(11): 1053-1059.
(C) This work is licensed under Creative

Submission Link: http://biomedres.us/submit-manuscript.php

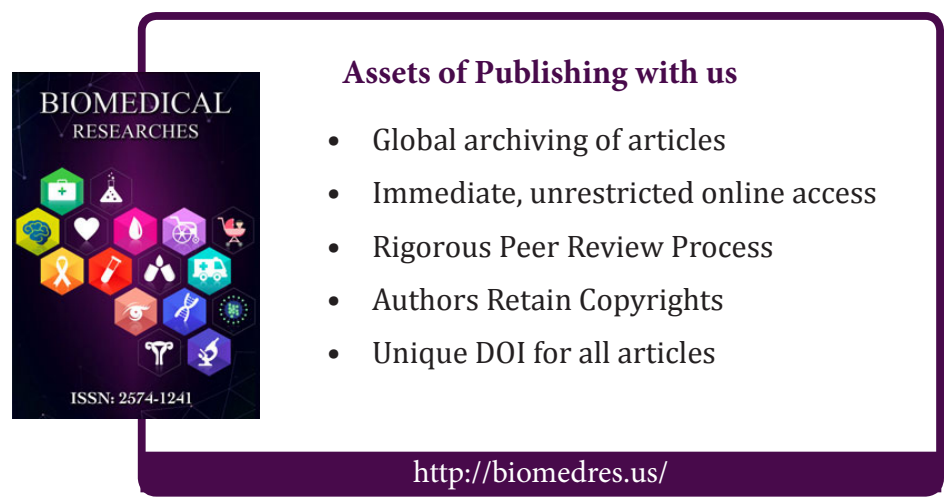

